\title{
Undrained anisotropy and non-coaxial behavior of clayey soil under principal stress rotation*
}

\author{
Jian ZHOU ${ }^{\dagger}$, Jia-jia YAN ${ }^{\dagger \ddagger}$, Zheng-yi LIU, Xiao-nan GONG \\ (Research Center of Coastal and Urban Geotechnical Engineering, Zhejiang University, Hangzhou 310058, China) \\ †E-mail: zjelim@zju.edu.cn; yanjia.01@163.com
}

Received Aug. 22, 2013; Revision accepted Feb. 16, 2014; Crosschecked Mar. 17, 2014

\begin{abstract}
In this study, a series of undrained tests were conducted on both intact and reconstituted clay using an automatic hollow cylinder apparatus. Monotonic shearing tests with fixed principal stress directions were carried out, pure and cyclic principal stress rotation tests were also performed. The non-coaxiality, defined as the non-coincidence of the principal plastic strain increment direction and the corresponding principal stress direction, of clayey soil was studied experimentally. The effects of the intermediate principal stress, shear stress level, and inherent anisotropy were highlighted. Clear non-coaxiality was observed during pure principal stress rotation, in both intact and reconstituted clay. The influence of the intermediate principal stress parameter, shear stress level, and inherent anisotropy on the non-coaxial behavior of the clayey soil was found to be insignificant when compared with the sand. The non-coaxial behavior of the clayey soil depended more on the stress paths. Under undrained conditions, the contribution of elastic strain to the direction of the total principal strain increment cannot be ignored.
\end{abstract}

Key words: Non-coaxiality, Clay, Principal stress rotation, Anisotropy doi:10.1631/jzus.A1300277 Document code: A CLC number: TU411.99

\section{Introduction}

In conventional elastic-plastic constitutive theory, the direction of the principal plastic strain increment should always coincide with the direction of the corresponding principal stress. This is known as Saint-Venant's principle. This rule does not always apply to geo-materials and many laboratory tests have provided clear evidence for soil non-coaxiality, especially under the stress paths involved with principal stress rotation (Miura et al., 1986; Wong and Arthur, 1986; Gutierrez et al., 1991; Lade and Kirkgard, 2000; Lade et al., 2009; Cai, 2010; Tong et al., 2010; Cai et al., 2013; Yan et al., 2013).

It is important to take the non-coaxiality of soil into consideration in the evaluation of soil behavior,

\footnotetext{
${ }^{\ddagger}$ Corresponding author

* Project supported by the National Natural Science Foundation of China (Nos. 51338009, 51078329, and 51178422)

(C) Zhejiang University and Springer-Verlag Berlin Heidelberg 2014
}

e.g., in strain localization (Nakata et al., 1997) and in predicting shear band formation with bifurcation theory (Gutierrez and Ishihara, 2000). Numerical studies carried out by Yang and $\mathrm{Yu}$ (2006) and $\mathrm{Yu}$ and Yuan (2006) showed that geotechnical design without taking the effects of non-coaxial soil behavior into consideration may be unsafe, as soil deformations may be underestimated. Thus, it is important to investigate soil non-coaxiality to understand soil behavior and conduct constitutive modeling properly.

Roscoe et al. (1967) were among the first to report that the direction of the principal strain increment did not coincide with the principal stress direction in simple shear tests. The deviation can be as large as $25^{\circ}$ in the early stage of shearing. The deviation decreased as the shear strain increased, and the behavior was almost coaxial at failure. Non-coaxial behavior in sand was also observed in tests with controlled principal stress rotation with a hollow cylinder apparatus. Undrained and drained tests on sand with fixed principal stress directions $\left(24.5^{\circ}\right.$ and $45^{\circ}$ to the 
vertical) and a pure principal stress rotation $\left(0^{\circ}-45^{\circ}\right)$ were carried out by Symes et al. $(1984 ; 1988)$. They found that the deviation between the direction of the principal stress and the direction of the principal strain increment could be approximately $18^{\circ}$ in the fixed principal stress direction tests for drained and undrained sand. In pure rotation tests, the maximum deviation could be $50^{\circ}$ for undrained conditions and $38^{\circ}$ for drained conditions at the beginning of rotation In drained tests carried out by Miura et al. (1986), Gutierrez et al. (1991), and Cai (2010), the noncoaxiality of sand in fixed principal stress direction tests was relatively small $\left(<11^{\circ}\right)$ and decreased as the shear stress increased. Thus, it could be ignored from a practical perspective. However, in tests involving a pure principal stress rotation, non-coaxiality was also significant. Torsion shear tests on sand carried out by Lade et al. (2009) showed that the direction of the major principal strain increment appeared to be coinciding with the direction of the major principal stress at failure as the cross-anisotropy of pluviated sand had been erased. Non-coaxiality of $30^{\circ}$ in sand under principal stress rotation was also observed by Wong and Arthur (1986) in tests conducted using a directional shear cell apparatus.

Pradel et al. (1990), Gutierrez et al. (1991), and Ohkawa et al. (2011) conducted stress probe tests, and showed that the plastic strain increment direction was strongly dependent on the direction of the stress increment. Gutierrez et al. (1991) also noted that both the magnitude and the direction of stress influenced the direction of the plastic strain increment. The non-coaxial behavior of sand under drained conditions was studied extensively by Cai et al. (2013). The stress level, stress path, initial anisotropy, and relative density were all found to influence the non-coaxial behavior of sand. In their tests, in which equal internal and external pressures were used, the influence of the intermediate principal stress could not be studied, and the total strain, rather than the plastic strain, was analyzed. Nakata et al. (1997) proved experimentally that drained non-coaxiality behavior occurred irrespective of the degree of anisotropy of the sand, based on pure principal stress rotation tests on both airpluviated and rodded sand specimens. In their tests, the mean stress, the intermediate principal stress parameter, and the shear stress were all kept constant during the principal stress rotation. They noted that the influence of the intermediate principal stress on non-coaxiality should be taken into consideration, as it is well known that the intermediate principal stress has a significant influence on the stress-strainstrength properties of soil (Sãyao and Vaid, 1996; Kumruzzaman and Yin, 2010).

Non-coaxial behavior was also observed by Lade and Kirkgard (2000) in intact soft clay when failed in undrained tests with a fixed principal stress direction. However, undrained torsion shear tests conducted on Edgar Plastic Kaolinite by Hong and Lade (1989) showed that the direction of the major principal strain increment coincided with the major principal stress increment direction at small shear strain, but as the shear stress increased, the major principal strain increment direction approached and essentially coincided with the major principal stress direction. Non-coaxial behavior in intact clay subjected to principal stress rotation was studied by Yan et al. (2013). The shear stress level, torsional shear strain, and principal stress rotation direction were found to influence the non-coaxial behavior of intact clay. By comparison with non-coaxial behavior in sand, non-coaxial behavior in clay has not yet been much studied, especially under complex stress paths with principal stress rotation.

In drained tests on sand, the direction of the principal plastic strain increment was observed to be almost the same at the direction of the total principal strain increment, especially at higher shear stress levels, and the effect of the elastic strain on the direction of the total principal strain increment was observed to be negligible (Gutierrez and Ishihara, 2000). So non-coaxiality is defined as the noncoincidence between the directions of the total principal strain increment and the principal stress directions (Roscoe et al., 1967; Wong and Arthur, 1986; Cai et al., 2013). In undrained tests, the effect of the elastic strain is more pronounced than it is in drained tests. Thus, the non-coaxiality was defined as the deviation between the directions of the principal plastic strain increment and the principal stress in this study, and the plastic flow behavior of clayey soil subjected to a principal stress rotation in undrained condition was investigated.

A series of tests were carried out on clayey soil using an automatic hollow cylinder apparatus. The non-coaxial behavior of clay subjected to stress paths involving a fixed principal stress direction, pure 
principal stress rotation, and cyclic principal stress rotation was investigated. The influence of the shear stress level, intermediate principal stress, inherent anisotropy, and stress path on the non-coaxial behavior of clayey soil was analyzed. Nakata et al. (1997) noted that when considering a basic framework for constitutive models, it is important to understand the non-coaxiality of soil with inherent isotropy; the non-coaxiality of both intact and reconstituted clay specimens was therefore investigated.

\section{Test apparatus, materials, and test procedures}

\subsection{Hollow cylinder apparatus (HCA)}

An advanced automatic hollow cylinder apparatus developed by Zhejiang University and GDS Instruments Ltd., UK was used in this study. Independently controlled axial load $W$, torque $M_{\mathrm{T}}$, inner cell pressure $p_{\mathrm{i}}$, and outer cell pressure $p_{\mathrm{o}}$ were applied to a hollow cylindrical specimen with a geometry of $30 \mathrm{~mm} \times 50 \mathrm{~mm} \times 200 \mathrm{~mm}$ (inner radius $\times$ outer radius $\times$ height). Under a combination of loadings, the axial stress $\sigma_{\mathrm{z}}$, shear stress $\tau_{\mathrm{z} \theta}$, radial stress $\sigma_{\mathrm{r}}$, and circumferential stress $\sigma_{\theta}$ (Fig. 1) can all be controlled independently, which allows a wide range of engineering problems to be considered that could not be simulated in triaxial tests. $\alpha$ is the major principal stress direction with respect to the vertical axis, and $\sigma_{1}$, $\sigma_{2}, \sigma_{3}$ are the principal stresses. Dynamic axial loading or displacement is produced by a high-power brushless DC servomotor. Dynamic torque or torsional displacement, which actuates by a second servomotor, is added to the axial motion by means of a splined shaft, and $\sigma_{\mathrm{r}}$ and $\sigma_{\theta}$ are controlled by $p_{\mathrm{i}}$ and $p_{0}$, respectively. The in-built encoders are used for measurements of torque/rotation and axial load/ displacement. The variations in the inner and outer radii are calculated from the axial displacement and the volume changes of the specimen and the inner cell chamber, assuming that the specimen remains cylindrical during testing. Details of this apparatus were provided by Shen (2007). Average stresses and strains were calculated according to the methods proposed by Hight et al. (1983).

The mean normal stress $p$, shear stress $q$, intermediate principal stress parameter $b$, and $\alpha$ were

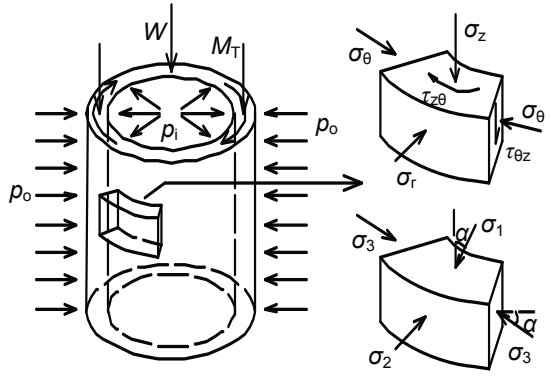

Fig. 1 Stress state of hollow cylinder specimens

used to describe the stress paths, i.e.,

$$
\begin{aligned}
& p=\left(\sigma_{1}+\sigma_{2}+\sigma_{3}\right) / 3=\left(\sigma_{\mathrm{z}}+\sigma_{\mathrm{r}}+\sigma_{\theta}\right) / 3, \\
& q=\left(\sigma_{1}-\sigma_{3}\right) / 2=\sqrt{\left(\sigma_{\mathrm{z}}-\sigma_{\theta}\right)^{2} / 4+\tau_{\mathrm{z \theta}}^{2}}, \\
& b=\frac{\sigma_{2}-\sigma_{3}}{\sigma_{1}-\sigma_{3}}=\frac{\frac{2 \sigma_{\mathrm{r}}-\sigma_{\mathrm{z}}-\sigma_{\theta}}{2}+\sqrt{\left(\frac{\sigma_{\mathrm{z}}-\sigma_{\theta}}{2}\right)^{2}+\tau_{z \theta}^{2}}}{\sqrt{\left(\sigma_{\mathrm{z}}-\sigma_{\theta}\right)^{2}+4 \tau_{z \theta}^{2}}}, \\
& \alpha=\frac{1}{2} \arctan \left(2 \tau_{\mathrm{z \theta}} /\left(\sigma_{\mathrm{z}}-\sigma_{\theta}\right)\right),
\end{aligned}
$$

and the direction of the principal plastic strain increment with respect to the vertical axis can be calculated as

$$
\alpha_{\mathrm{d} \varepsilon^{\mathrm{p}}}=\frac{1}{2} \arctan \left(\mathrm{d} \gamma_{z \theta}^{\mathrm{p}} /\left(\mathrm{d} \varepsilon_{\mathrm{z}}^{\mathrm{p}}-\mathrm{d} \varepsilon_{\theta}^{\mathrm{p}}\right)\right)
$$

where $\mathrm{d} \varepsilon_{z}^{\mathrm{p}}, \mathrm{d} \varepsilon_{\theta}^{\mathrm{p}}$, and $\mathrm{d} \gamma_{z \theta}^{\mathrm{p}}$ are the increments of plastic axial strain, tangential strain, and torsional shear strain, respectively.

The degree of non-coaxiality can be expressed by the non-coaxial angle $\beta$, which is defined as

$$
\beta=\alpha_{\mathrm{d} \varepsilon^{\mathrm{p}}}-\alpha
$$

\subsection{Clay specimens}

Intact soft clay blocks were taken from an excavation pit $4 \mathrm{~m}$ below the ground level in the city of Hangzhou, China. The basic physical properties of this clay are summarized in Table 1. Samples reconstituted in the laboratory were also used for investigation. Clay powder was made into slurry at twice of the liquid limit. The slurry was consolidated isotropically at a vacuum pressure of $80 \mathrm{kPa}$ in a special 
consolidation device. It required more than $15 \mathrm{~d}$ to complete consolidation. A reconstituted clay block with $30 \mathrm{~cm}$ in radius and $35 \mathrm{~cm}$ in height is shown in Fig. 2a.

A special sample kit was used for sample preparation (Shen, 2007). The intact and reconstituted clay blocks were trimmed into hollow cylindrical specimens as given in Fig. 2b. Filter paper strips were then pasted around the outer surfaces of the specimens to equalize the pore water pressure and reduce consolidation time. The specimens were each assembled in the HCA to be saturated at a backpressure of $100 \mathrm{kPa}$, ensuring that Skempton's pore pressure parameter $B$ was higher than 0.98 . An examination of the clay sampling methods and the repeatability of the HCA was carried out by Zheng (2011), and showed excellent repeatability of the test results and negligible effects of specimen preparation and assembly.

\subsection{Testing procedures}

Three series of tests were carried out: (1) stress paths applied with a fixed principal stress direction (T-series), (2) pure principal stress rotation (R-series), and (3) cyclic principal stress rotation (C-series). All the specimens were isotropically consolidated under an effective stress of $p=150 \mathrm{kPa}$ at first.

In the T-series tests, after isotropic consolidation, monotonic shear tests were carried out by increasing the shear stress $q$ to failure using a stress path control system with the principal stress direction fixed. As indicated in Fig. $3(\mathrm{OE})$, the stress path was a straight line from the original. $\alpha$ was fixed at $0^{\circ}, 30^{\circ}, 45^{\circ}, 60^{\circ}$, and $90^{\circ}$ during monotonic shearing. Throughout all of the T-series tests, $p$ and $b$ were held constant at $150 \mathrm{kPa}$ and 0.5 , respectively. The T-series test plan is listed in Table 2. Both the non-coaxial behavior and the inherent anisotropy of the two types of soil specimens were examined.

In the R-series tests, specimens were monotonically sheared to an initial shear stress $q_{0}$ with $\alpha=0^{\circ}$ after consolidation to point $A$ in Fig. 3. $b$ was also increased to the values listed in Table 3 . The principal stress was then rotated from $0^{\circ}$ to $360^{\circ}$ (two cycles) at a constant rate of $0.2 \%$ min (shear stress rate of $0.17 \mathrm{kPa} / \mathrm{min}$ ), following the stress path of $A \rightarrow B \rightarrow$

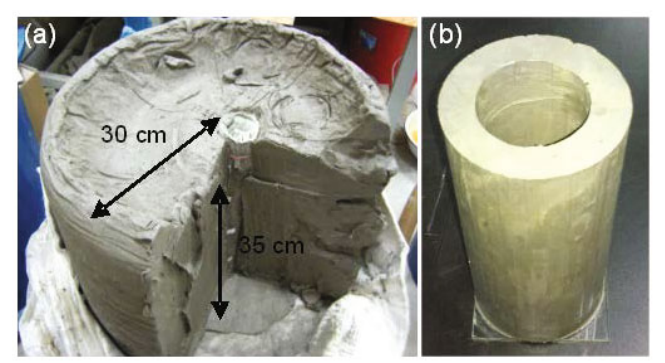

Fig. 2 Reconstituted clay block (a) and test clay specimen (b)

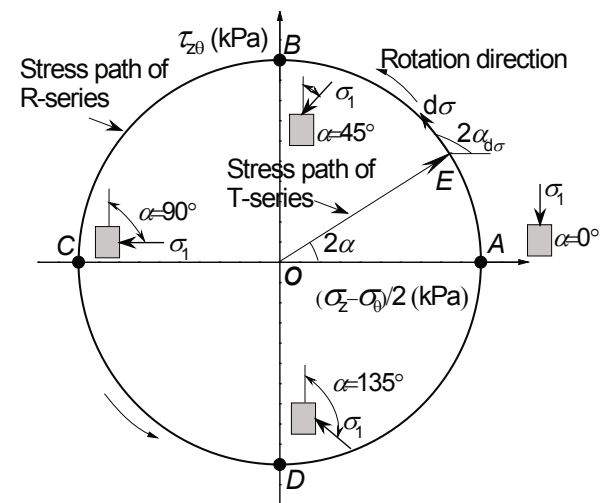

Fig. 3 Indication of stress paths

Table 1 Physical properties of intact clay

\begin{tabular}{cccccc}
\hline Specific gravity, & Liquid limit, & Plastic limit, & Plasticity index, & Natural density, & Natural water content, \\
$G_{\mathrm{s}}$ & $w_{\mathrm{l}}(\%)$ & $w_{\mathrm{p}}(\%)$ & $I_{\mathrm{p}}$ & $\rho\left(\mathrm{g} / \mathrm{cm}^{3}\right)$ & $w(\%)$ \\
\hline 2.68 & 49.8 & 22.8 & 27 & 1.78 & 42.2 \\
\hline
\end{tabular}

Table 2 Monotonic shear tests

\begin{tabular}{ccccc||ccccc}
\hline No. & $p(\mathrm{kPa})$ & $b$ & $\alpha\left(^{\circ}\right)$ & Soil type & No. & $p(\mathrm{kPa})$ & $b$ & $\alpha\left(^{\circ}\right)$ & Soil type \\
\hline T11 & & & 0 & & T21 & & & 0 & \\
T12 & & & 30 & & T22 & & & 30 & \\
T13 & \multirow{2}{*}{150} & 0.5 & 45 & Intact clay & T23 & 150 & 0.5 & 45 & Reconstituted clay \\
T14 & & & 60 & & T24 & & & 60 & \\
T15 & & & & T25 & & & 90 & \\
\hline
\end{tabular}


$C \rightarrow D \rightarrow A$ shown in Fig. 3. The effect of $q, b$, and inherent anisotropy on the non-coaxial response of clay during pure principal stress rotation was analyzed.

In the $\mathrm{C}$-series tests (Table 4), specimens were first sheared to $q=25 \mathrm{kPa}$ with $b=0.5$ after consolidation. The direction of the principal stress was then rotated cyclically between $0^{\circ}$ and $45^{\circ}(A \leftrightarrow B$ in Fig. 3) with constant $p, q$, and $b$. Eight cycles in total were performed in each test. The non-coaxiality and the elastic behaviors of the specimens under cyclic principal stress rotation were investigated.

\section{Experimental}

\subsection{Stress-strain relationship}

Monotonic shear tests with fixed principal stress directions were carried out on both intact and reconstituted clay specimens. Curves of the shear stress $q$, versus the deviatoric strain $\varepsilon_{q}$ obtained from the Tseries tests are shown in Fig. 4, where

$$
\varepsilon_{q}=\sqrt{2\left(\left(\varepsilon_{1}-\varepsilon_{2}\right)^{2}+\left(\varepsilon_{2}-\varepsilon_{3}\right)^{2}+\left(\varepsilon_{3}-\varepsilon_{1}\right)^{2}\right) / 9},
$$

where $\varepsilon_{1}, \varepsilon_{2}$, and $\varepsilon_{3}$ are the principal strains.

Similar stress-strain behavior was observed in all of the tests. The specimens were sheared in stresscontrolled mode. The shear strain increased gradually as the shear stress increased. No peak shear stress was reached in most of the tests, so the tests terminated with a large shear strain (when an obvious shear band developed). The shear stress at the shear strain reached $8 \%$ was taken as the shear strength in these tests (Zheng, 2011).
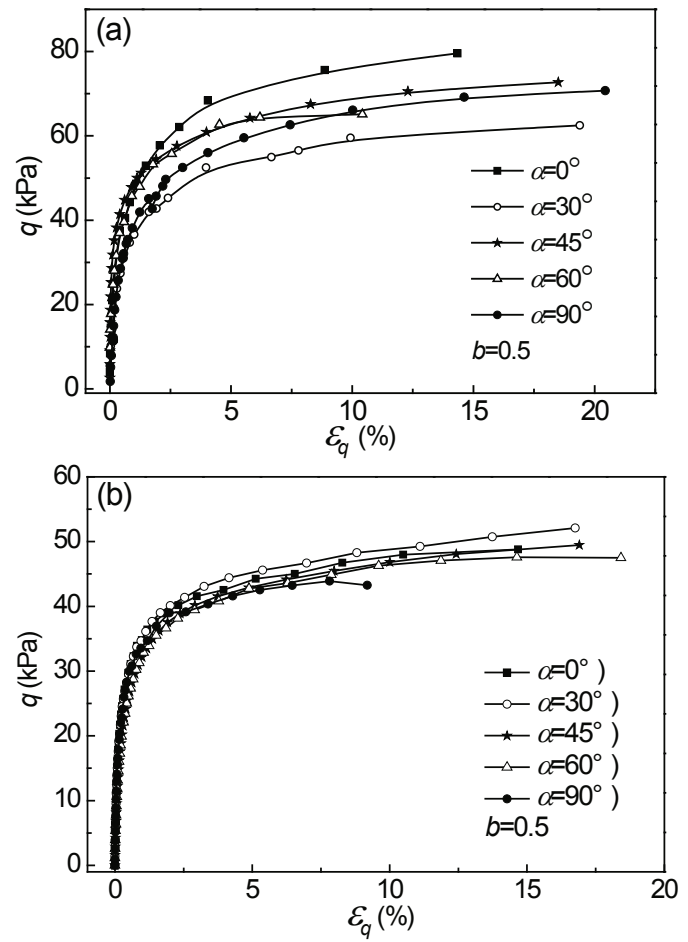

Fig. 4 Shear stress-strain curves from the T-series tests (a) Intact clay; (b) Reconstituted clay

Table 3 Pure rotation tests

\begin{tabular}{ccccccc}
\hline & Test No. & $p(\mathrm{kPa})$ & $q_{0}(\mathrm{kPa})$ & $b$ & $\alpha\left(^{\circ}\right)$ & Soil type \\
\hline \multirow{5}{*}{ Series-R1 } & RI1 & & 37.5 & 0 & & \\
& RI2 & & 37.5 & 0.25 & & Intact clay \\
& RI3 & \multirow{2}{*}{150} & 37.5 & 0.50 & 360 & \\
& RI4 & & 37.5 & 0.75 & & \\
& RI5 & & 37.5 & 1.00 & & Intact clay \\
& RI6 & & 25.0 & 1.00 & & \\
\hline \multirow{3}{*}{ Series-R2 } & RI5 & \multirow{2}{*}{150} & 37.5 & 1.00 & 360 & Reconstituted clay \\
& RI7 & & 50.0 & 1.00 & & \\
\hline
\end{tabular}

Table 4 Cyclic rotation tests

\begin{tabular}{ccccccc}
\hline Test No. & $p(\mathrm{kPa})$ & $q_{0}(\mathrm{kPa})$ & $b$ & $\alpha\left(^{\circ}\right)$ & Number of cycles & Soil type \\
\hline $\mathrm{RC} 1$ & 150 & 25 & 0.5 & $0 \rightarrow 45 \rightarrow 0$ & 8 & Intact clay \\
$\mathrm{RC} 2$ & 150 & 25 & 0.5 & $0 \rightarrow 45 \rightarrow 0$ & 8 & Reconstituted clay \\
\hline
\end{tabular}


Fig. 4a shows the shear stress-strain curves for intact clay under monotonic shearing. It is apparent that the undrained resistance of intact clay is strongly dependent on the shearing direction. The maximum shear resistance occurred at $\alpha=0^{\circ}$ while the minimum shear stress resistance occurred at $\alpha=30^{\circ}$. The failure envelope of intact clay shown in Fig. 5 indicates the significant inherent anisotropy of the intact clay specimens.

The reconstituted clay samples behaved more isotropically than the intact clay (Fig. 4b). The shear stress-strain curves of the laboratory-molded specimens sheared in different directions were almost the same. The failure envelope of the reconstituted clay is also shown in Fig. 5. It is approximately a circle. The shear strength of the reconstituted clay was much lower than that of the intact clay. This suggests that the soil strength is diminished when the initial soil structure is destroyed.

As mentioned above, in the R-series tests, the parameters $p, q$, and $b$ were held constant during the principal stress rotation. The stress components of $\sigma_{\mathrm{z}}$, $\sigma_{\theta}, \sigma_{\mathrm{r}}$, and $\tau_{\mathrm{z} \theta}$ vary with $\alpha$ as shown in Eqs. (7)-(10).

$$
\begin{aligned}
\sigma_{\mathrm{z}} & =p-(2 b q-q) / 3+q \cos (2 \alpha), \\
\sigma_{\mathrm{r}} & =p+2(2 b q-q) / 3, \\
\sigma_{\theta} & =p-(2 b q-q) / 3-q \cos (2 \alpha), \\
\tau_{\mathrm{z} \theta} & =q \sin (2 \alpha) .
\end{aligned}
$$

The constant principal stresses can be obtained by

$$
\begin{aligned}
& \sigma_{1}=p-(2 b q-4 q) / 3 \\
& \sigma_{2}=p+2(2 b q-q) / 3 \\
& \sigma_{3}=p-(2 b q+2 q) / 3 .
\end{aligned}
$$

Taking test RI3 ( $b=0.5, q=37.5 \mathrm{kPa})$ as an example, the variation in the stress components of $\sigma_{\mathrm{z}}, \sigma_{\theta}$, $\sigma_{\mathrm{r}}$, and $\tau_{\mathrm{z} \theta}$ with the principal stress direction of the pure principal stress rotation is illustrated in Fig. 6. In the R-series tests, the variation in the stress components was the same as for RI3, only the magnitude varied, depending on the values of $b$ and $q$, according to Eqs. (7)-(13).

The variation in the strain components with the major principal stress direction of intact clay is illustrated in Fig. 7. The strains varied with the continuous principal stress rotation, and deformation accumulated even with constant $p, q$, and $b$. The variations in the strain curves were similar to those of the stresses shown in Fig. 6a, while the strain curves lagged behind the stress components by approximately $20^{\circ}$. Taking axial strain and stress as examples, $\sigma_{\mathrm{z}}$ reached its minimum value at $\alpha=90^{\circ}$ (Eq. (7)), but the minimum $\varepsilon_{\mathrm{z}}$ occurred at approximately $\alpha=110^{\circ}$ in the first cycle (Fig. 7a). Strain components lagging behind stresses by $20^{\circ}$ was also observed by Miura et al. (1986) in drained tests on sand.

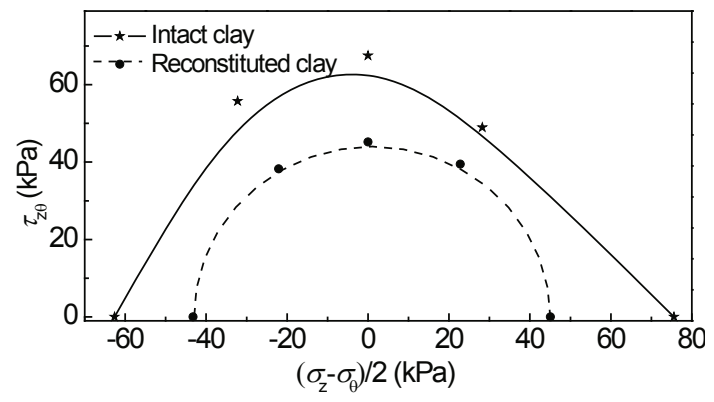

Fig. 5 Failure envelope from the T-series tests
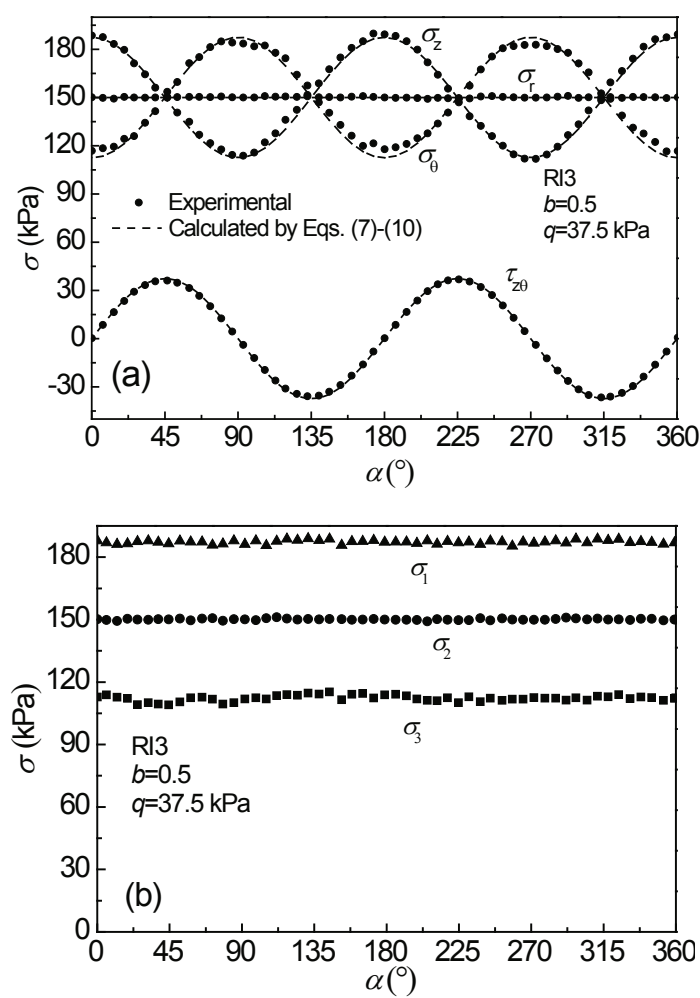

Fig. 6 Variation in the stress components on RI3 during rotation (a) and principal stresses of RI3 (b) 
The axial strains increased slightly at the beginning of the principal stress rotation $\left(0^{\circ}-20^{\circ}\right)$, then decreased when $\alpha$ was increased to $110^{\circ}$, and then increased again when $\alpha$ increased to $180^{\circ}$. The variation in the axial strains during the second cycle was the same as in the first cycle. After two full cycles of pure principal stress rotation, the specimens were compressed in the vertical direction with $b<1$, but the specimen with $b=1$ was extended. The development of circumferential strain was opposite to that of the axial strain, which is consistent with the variation in stress shown in Fig. 6a. Specimens were compressed in the circumferential direction with $b=0$ and 0.25 and extended with $b=0.5,0.75$, and 1 . Specimens were extended in the radial direction with $b<0.5$ and compressed with $b>0.5$.

A comparison of the strain curves for different $b$ values shows that $b$ has an obvious influence on the development of strain induced by pure principal stress rotation. Strain developed more quickly with $b=1$ during principal stress rotation (especially in the axial and radial directions). As Fig. 7c shows, the radial strain measured in RI3 was almost zero throughout the rotation, i.e., close to the plane strain condition.
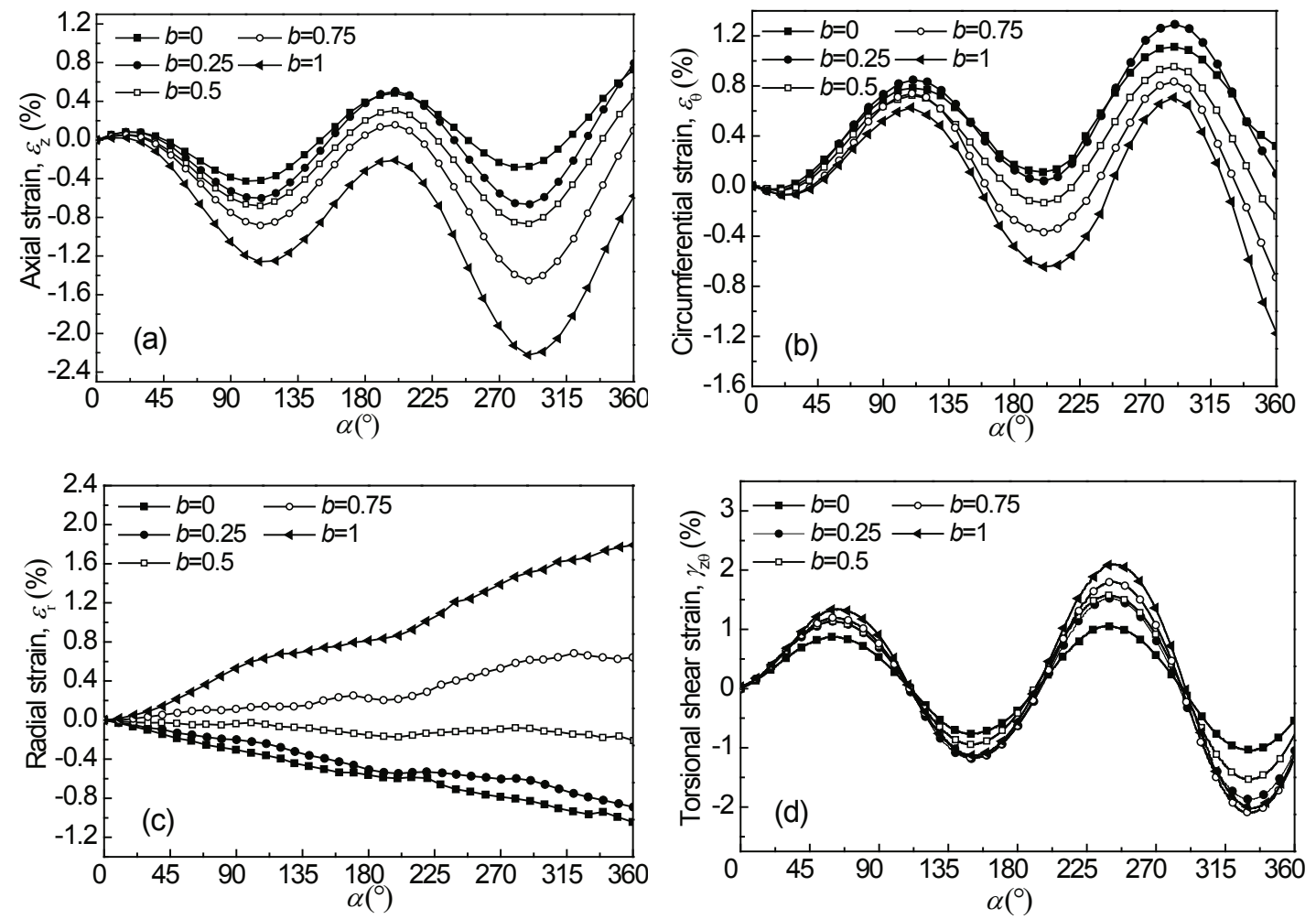

Fig. 7 Variation in axial (a), circumferential (b), radial (c), and torsional shear (d) strains with principal stress direction for Series R1 

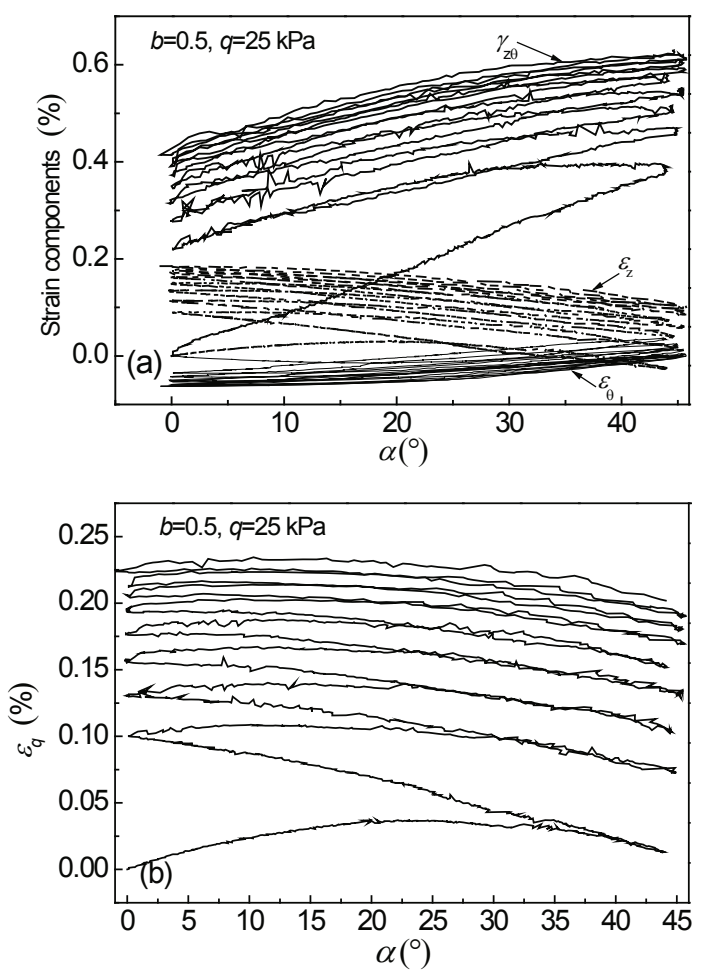

Fig. 8 Variation of strain with the number of cycles of RC1

(a) Strain components; (b) Deviatoric shear strain
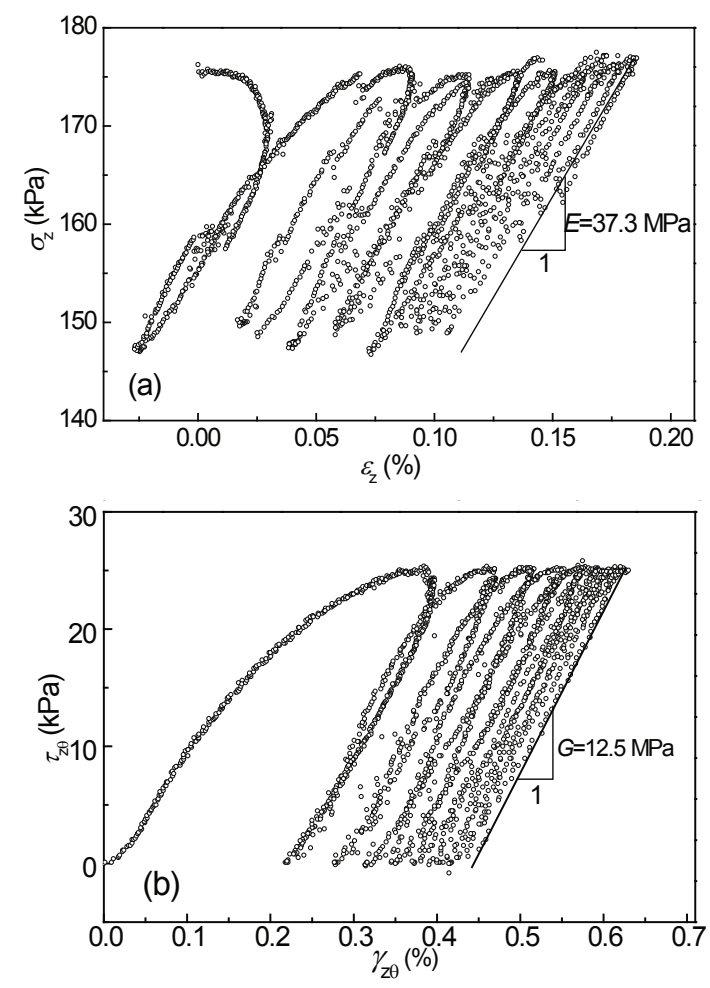

Fig. 9 Stress-strain curves of RC1

(a) Axial; (b) Torsional where $\mathrm{d} \varepsilon_{i j}$ is the total strain increment and $\mathrm{d} \varepsilon_{i j}^{\mathrm{e}}$ is the elastic strain increment. The elastic strain component was calculated according to Hooke's Law using the elastic parameters obtained from the cyclic rotation tests.

\subsection{Non-coaxial behavior of clay}

\subsubsection{Monotonic shear tests}

The directions of the principal plastic strain increments in the T-series tests are shown in Fig. 10. For $\alpha=0^{\circ}$ and $90^{\circ}$, the specimens were under triaxial compression and tension, respectively. The principal plastic strain was forced to increase in the direction of the major principal stress, so the specimens behaved coaxially. When the principal stress direction was fixed at other angles $\left(\alpha=30^{\circ}, 45^{\circ}\right.$, and $\left.60^{\circ}\right)$, the deviation between the directions of the principal plastic strain increment and the principal stress could be observed for both intact and reconstituted clay. The maximum non-coaxial angles of $9^{\circ}$ for intact clay and $4^{\circ}$ for reconstituted clay were observed when $\alpha$ was fixed at $30^{\circ}$. Deviations still existed when specimens were failed with $\alpha$ fixed at $30^{\circ}$ and $60^{\circ}$, as reported by Symes et al. (1984) for undrained tests on sand.

The non-coaxial angle was positive $\left(\alpha_{\mathrm{d}^{\mathrm{p}}}>\alpha\right)$ when $\alpha<45^{\circ}$, and tended to be negative when $\alpha>45^{\circ}$, which was also found in tests on sand (Miura et al., 1986; Gutierrez et al., 1991; Cai et al., 2013). Cai et al. (2013) attributed this phenomenon to the irregular shape of the failure envelope, i.e., the direction of the principal strain being perpendicular to the failure envelope at failure. However, this cannot explain the non-coaxial behavior of reconstituted clay, the failure envelope of which is nearly circular. The failure envelope for the sand tested by Gutierrez et al. (1991) was also circular. Based on the similar non-coaxial behavior of soil subjected to identical stress paths, this phenomenon may be considered to be dependent on the stress path.

A comparison of the non-coaxial behavior of intact and reconstituted clay sheared with the principal stress direction fixed shows that the influence of inherent anisotropy on the non-coaxial behavior of clayey soil under this stress path is not obvious.

\subsubsection{Pure rotation tests}

Fig. 11a illustrates the variation in the noncoaxial angle $\left(\alpha_{\mathrm{d} \varepsilon^{\mathrm{p}}}-\alpha\right)$ of the intact clay with the 
direction of the major principal stress for various $b$ values (Series R1). Obvious deviations of the principal plastic strain increment direction from the direction of principal stress can be observed. The noncoaxial angle fluctuated throughout the rotation stage. The non-coaxial angles of the intact clay varied primarily within the range $10^{\circ}-25^{\circ}$. The degree of noncoaxiality was small at the beginning of the principal stress rotation. The non-coaxial angle increased to approximately $23^{\circ}$ when the principal stress rotated to $90^{\circ}$, it decreased to approximately $19^{\circ}$ when the principal stress rotated to $135^{\circ}$, and then it increased again to approximately $25^{\circ}$ when the principal stress rotated to $180^{\circ}$. The variation in the non-coaxial angle in the second cycle was similar to that in the first cycle. The average non-coaxial angle was $24^{\circ}$ in the second cycle, which was slightly larger than that in the first cycle (average $\beta=20.3^{\circ}$ ). These observations agree well with the results of drained pure principal stress rotation tests on sand conducted by Nakata et al. (1997). However, the tests on sand conducted by Tong et al. (2010) indicated that the non-coaxiality of sand has segmentation characteristics: the direction of the principal strain increment almost coincides with the principal stress increment direction in the rotation ranges of $45^{\circ}-90^{\circ}$ and $135^{\circ}-180^{\circ}$. This may be attributed to the influence of elastic strain, as the total principal strain increment was analyzed in their research.

To analyze the influence of elastic strain components, the deviations between the directions of the total principal strain increment and the corresponding principal stress are also shown in Fig. 11b. The deviations between the directions of the total principal strain increment and the principal stress (an average value of $27.5^{\circ}$ ) were larger than those between the directions of the principal plastic strain increment and the principal stress (an average value of $22.1^{\circ}$ ). Similar results were obtained in the drained tests on sand at low shear stress levels $(q / p<0.33)$ carried out by Gutierrez et al. (1991). These results indicate that the contribution of elastic strain to the direction of the total strain increment direction is not negligible for undrained conditions. Non-coaxial behavior defined
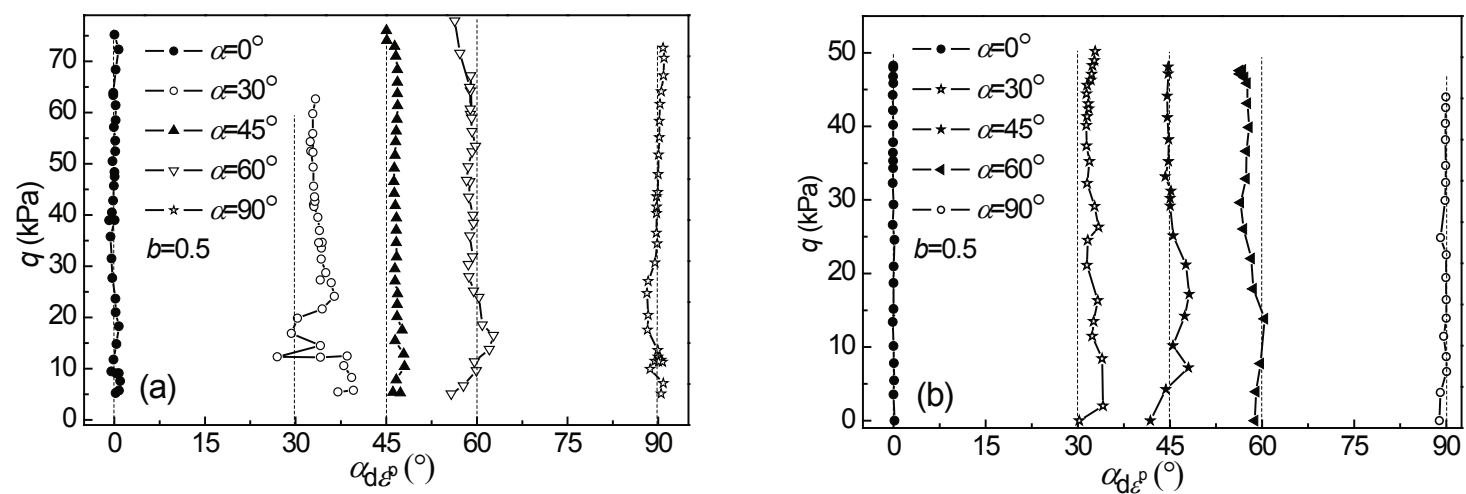

Fig. 10 Direction of principal plastic strain increment of T-series under intact clay (a) and reconstituted clay (b)
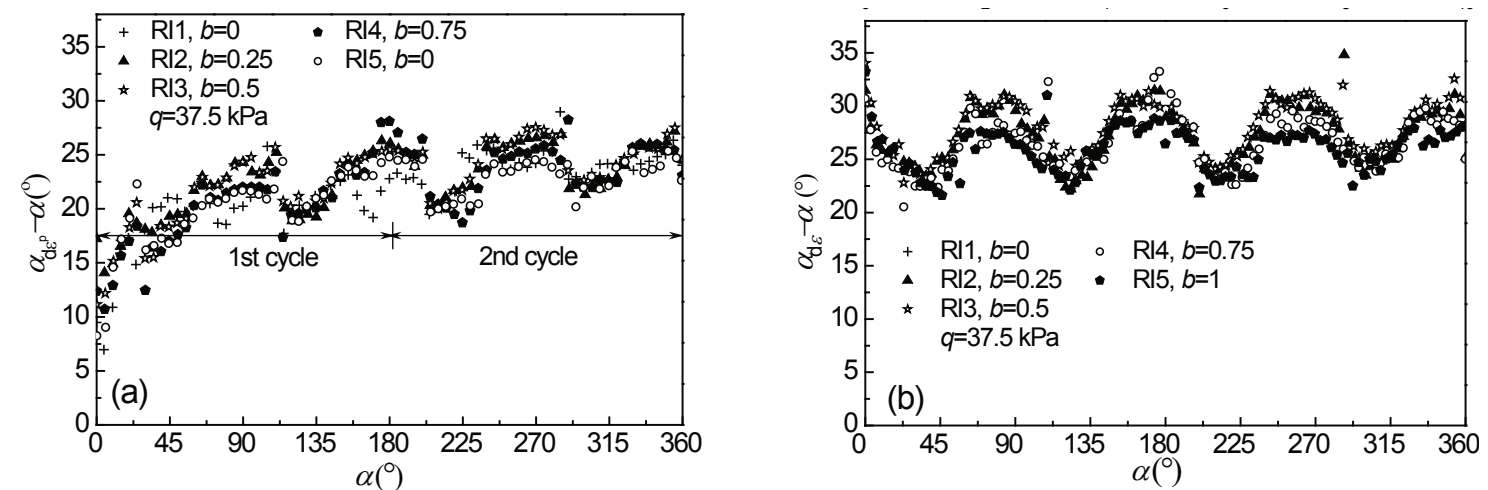

Fig. 11 Deviation between directions of $d \varepsilon^{\mathrm{p}}$ and $\alpha$ (a) and deviation between directions of $\mathrm{d} \varepsilon$ and $\alpha$ (b) of series R1 (intact clay) 
as the deviation between the directions of the total principal strain increment and the corresponding principal stress is inapt in this condition.

The non-coaxial angles of intact clay subjected to principal stress rotation at various shear stress levels (series R2) are shown in Fig. 12a. The non-coaxial angles fluctuated slightly with the rotation of the principal stress direction. The variation in the noncoaxial angles in the R2 series was very similar to that in the R1 series. The influence of the shear stress level on the deviation between the directions of the principal plastic strain increment and the principal stress was not as significant as that observed in tests on sand (Miura et al., 1986; Gutierrez et al., 1991; Cai et al., 2013). The non-coaxial angle of RI6 sheared with $q=25 \mathrm{kPa}$ was even smaller than that of the specimens sheared with $q=37.5 \mathrm{kPa}$ and $q=50 \mathrm{kPa}$ for $\alpha=0^{\circ}-150^{\circ}$. The non-coaxial angles of intact clay under rotational shearing were less influenced by the shear stress level in the second cycle.

The average non-coaxial angles of RI5, RI6, and RI7 were $21^{\circ}, 19^{\circ}$, and $19.6^{\circ}$, respectively. These results are in contrast to the findings of tests on sand,
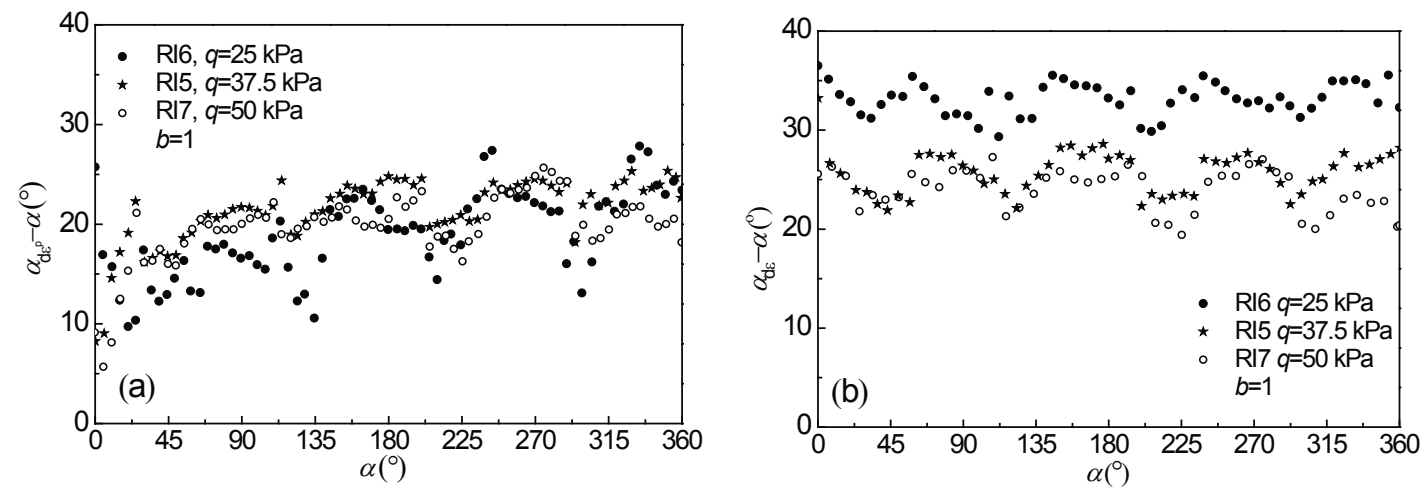

Fig. 12 Deviation between directions of $d \varepsilon^{\mathrm{p}}$ and $\alpha$ (a) and deviation between directions of $\mathrm{d} \varepsilon$ and $\alpha(\mathrm{b})$ of series R2 (intact clay)
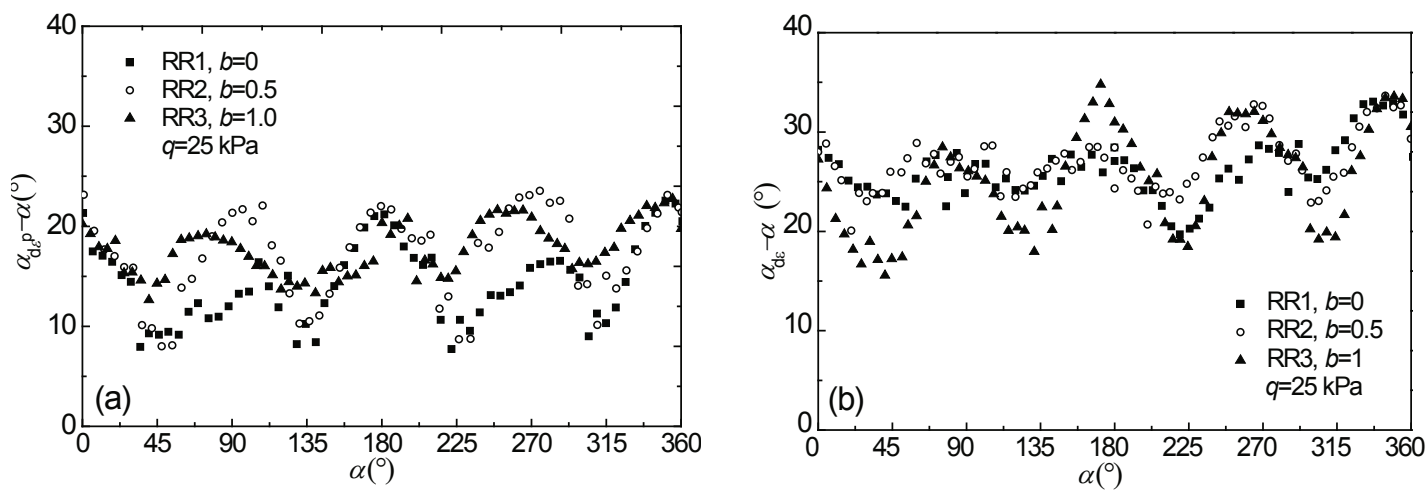

Fig. 13 Deviation between directions of $d \varepsilon^{\mathrm{p}}$ and $\alpha$ (a) and deviation between directions of $\mathrm{d} \varepsilon$ and $\alpha$ (b) of series R3 (reconstituted clay) 
$135^{\circ}-180^{\circ}$ in each cycle. The degree of non-coaxiality was the lowest (approximately $10^{\circ}$ ) at approximately $\alpha=45^{\circ}$ and $\alpha=135^{\circ}$. The non-coaxial angles of the reconstituted clay were larger than that of the intact clay at the beginning of the principal stress rotation, while in general, throughout the rotation stage, the non-coaxial angles of the intact clay (an average value of $22.1^{\circ}$ ) were larger than that of the reconstituted clay (an average value of $16.5^{\circ}$ ). The deviation between the total principal strain increment and the principal stress in series R3 is shown in Fig. 13b, which also illustrates the influence of elastic strain on the direction of the total principal strain increment.

The non-coaxial behavior of the intact and reconstituted clay specimens under pure principal stress rotation for various $b$ values is illustrated in Figs. 11a and Figs. 13a, respectively. The value of $b$ plays a significant role in strain development in intact clay subjected to pure principal stress rotation (Fig. 7). However, the influence of $b$ on the non-coaxial behavior of clayey soil subjected to pure principal stress rotation was not as obvious as on the development of strains. This observation is consistent with the results of tests on sand carried out by Tong et al. (2010). Thus, these experimental results suggest that the influence of the intermediate principal stress on the non-coaxial behavior of both clayey and granular soil is not significant and can be ignored in practical design.

\subsubsection{Cyclic principal stress rotation}

The total strain and plastic strain paths in the first cycle of RC1 were different (Fig. 14). Elastic strain was significant during the pure principal stress rotation. The total strain path turned when the principal stress rotated backward (from $45^{\circ}$ to $0^{\circ}$ ), while the plastic strain path did not turn immediately when the principal stress rotated in the reverse direction; rather, it turned at $\alpha=30^{\circ}$ (Fig. 14a).

The directions of both the principal plastic strain (triangles) and the total principal strain increments (solid squares) in the first cycle are shown in Fig. 14b. When the principal stress rotated from $0^{\circ}$ to $45^{\circ}$, the direction of the principal plastic strain increment lay between the directions of the principal stress and the principal stress increment, but it was much closer to the principal stress axis, and the average non-coaxial angle was $10.6^{\circ}$. The direction of the total principal
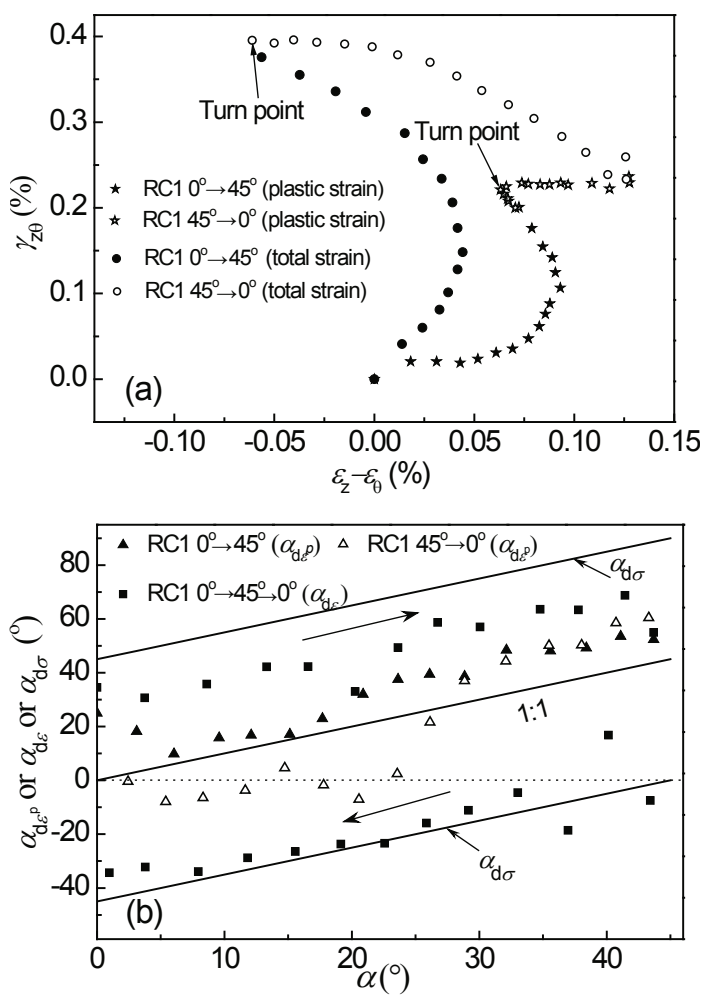

Fig. 14 Elastic and plastic strain paths (a) and directions of the principal strain and plastic strain increment (b) of $\mathrm{RC} 1$ in the 1st cycle

strain increment was closer to the direction of the principal stress increment, and the average deviation between the directions of the total principal strain increment and the principal stress was $25.6^{\circ}$. This is consistent with the results shown in Fig. 12, which illustrates that elastic strain has a significant effect on the direction of the total principal strain increment at lower shear stress level.

When the principal stress rotated from $45^{\circ}$ to $0^{\circ}$, the direction of the principal stress increment turned abruptly from $90^{\circ}$ to $0^{\circ}$. The angle of the total principal strain increment also decreased suddenly and was almost coaxial with the principal stress increment direction, which means that specimens are behaving almost elastically. This is consistent with the findings of Symes et al. (1984), who found that when a stress path of $\alpha$ rotated from $45^{\circ}$ to $0^{\circ}$ it involved unloading, and elastic strain was dominant during the unloading.

However, the direction of the principal plastic strain increment did not decrease abruptly. It was still larger than $\alpha$ when $\alpha$ rotated from $45^{\circ}$ to $30^{\circ}$. The non-coaxial angle became negative during $\alpha=30^{\circ}-0^{\circ}$. 
The direction of the principal plastic strain increment was still closer to the principal stress direction. This is consistent with the non-coaxial behavior of sand in swing tests (involving cyclic rotations between $-40^{\circ}$ and $40^{\circ}$, with $q / p=1 / 6$ and $b=0.5$ ) conducted by Nakata et al. (1997).

These results also demonstrate the influence of the stress path on the non-coaxial behavior. When the principal stress rotated backward (from $45^{\circ}$ to $0^{\circ}$ ), the non-coaxial angles were different from those observed when the principal stress rotated forward (from $0^{\circ}$ to $45^{\circ}$ ), even for identical principal stress directions $\left(0^{\circ}-30^{\circ}\right)$.

\section{Discussion}

\subsection{Effect of the elastic strain component}

Elastic strain increment directions are expected to be coaxial with the directions of stress increment (Hong and Lade, 1989). Thus, there was a constant deviation of $45^{\circ}$ between the directions of the elastic principal strain increment and the principal stress during pure principal stress rotation, as the stress increment direction is always perpendicular to the major principal stress axis (Fig. 15). Figs. 12-14 provide clear evidence of the significant contribution of elastic strain to the direction of the total strain increment. This contribution would be more significant if the elastic strain component was dominant in the total strain at lower shear stress levels. Undrained and drained pure principal stress rotation tests on medium to loose sand also indicated that the deviations between the directions of the principal stress and the total principal strain increment for undrained conditions are larger than those under drained conditions (Symes et al., 1984; 1988). Cyclic principal stress rotation tests on intact clay conducted by Yan et al. (2013) also showed that as the specimens behave more elastically as the number of cycles increased, the direction of the principal strain increment approached to the principal stress increment direction. All these observations suggest that the degree of noncoaxiality of soil may be overestimated for undrained conditions if the non-coaxial behavior is defined as the deviation between the directions of the total principal strain increment and the corresponding principal stress, especially at low shear stress levels.

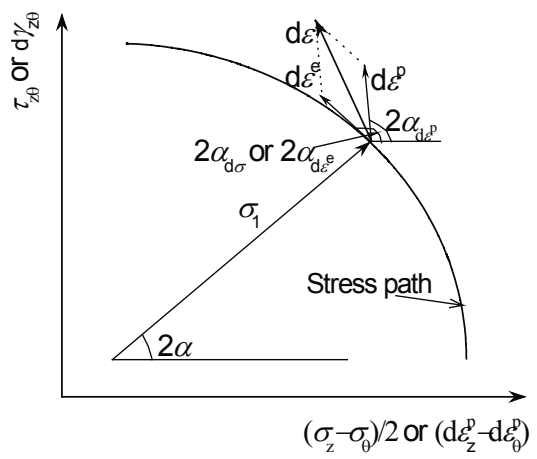

Fig. 15 Effect of elastic strain on total strain increment direction

\subsection{Effect of inherent anisotropy}

The non-coaxial behavior of sand has been attributed to its initial anisotropy by Miura et al. (1986) and Cai (2010). However, non-coaxiality has also been observed in tests on reconstituted clay, rodded sand (Nakata et al., 1997) and isotropic discrete element method (DEM) specimens (Cai et al., 2013). The non-coaxial angles of isotropic and anisotropic sand, clay, and DEM specimens during pure principal stress rotation under similar stress ratios are shown in Fig. 16. The rodded sand specimens in the tests conducted by Nakata et al. (1997) were more isotropic than the air-pluviated one. Note that the deviation between the total principal strain increment direction and the principal stress direction was defined as the non-coaxial angle by Cai et al. (2013), so the degree of non-coaxiality was much larger.

Fig. 16 provides clear evidence of the noncoaxial behavior of inherently isotropic soils when subjected to pure principal stress rotation. From this perspective, the non-coaxial behavior of soils may not totally depend on the inherent anisotropy of soils. Li and $\mathrm{Yu}(2013 \mathrm{a} ; 2013 \mathrm{~b})$ demonstrated that the noncoaxility between the force anisotropy and the fabric anisotropy is the main cause leading to the deformation non-coaxiality of anisotropic sand. Stress probing tests on dense Toyoura sand carried out by Ohkawa et al. (2011) also showed that non-coaxiality of sand was induced by the stress increment direction. Thus, based on the similar non-coaxial behavior of soil materials under identical stress paths, it can be concluded that the non-coaxial behavior of soil may depend more on the stress paths. 


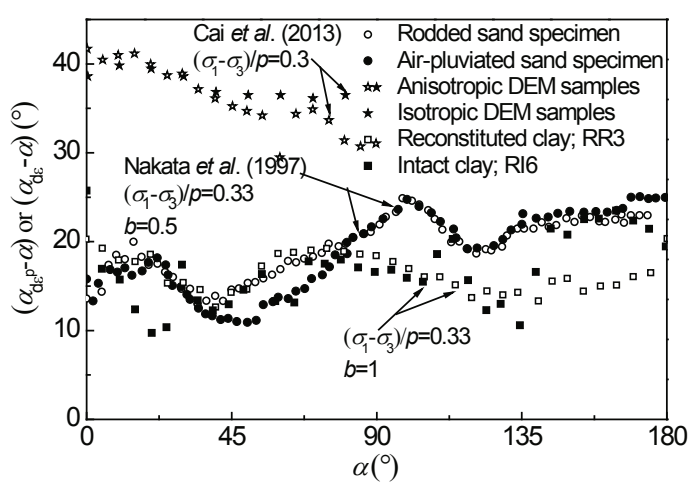

Fig. 16 Non-coaxial angles of sand, clay, and DEM specimens

\section{Conclusions}

The non-coaxial behavior of clayey soil was examined in this study, based on the results of several tests conducted on intact and reconstituted clay specimens. Monotonic shearing tests with fixed principal stress directions, continuous pure principal stress rotation tests, and cyclic principal stress rotation tests with constant mean normal stress, shear stress, and the intermediate principal stress parameter were performed. The test results were also compared with the results of similar tests on sand. The following conclusions can be drawn from the experimental results:

1. The reconstituted clay behaved almost isotropically, with a similar stress-strain relation when sheared in different directions. The non-coaxial behavior of both the intact and reconstituted clay in $\mathrm{T}$-series tests was not obvious, and can be ignored in practical design.

2. Plastic strain was induced by principal stress rotation alone. A significant deviation was observed between the directions of the principal plastic strain increment and the principal stress in both intact and reconstituted clay. The influence of the intermediate principal stress parameter on the non-coaxial behavior was found not as obvious as on the strains.

3. Under undrained conditions, the contribution of the elastic strain component to the total strain increment direction during pure principal stress rotation was pronounced. The effect of elastic strain was more obvious at lower shear stress levels.

4. The non-coaxial behavior of soil cannot be attributed to inherent soil anisotropy alone. The di- rection of the principal plastic strain increment was highly dependent on the direction of the principal stress increment, thus, the stress path has an important influence on the non-coaxial behavior of clayey soil.

\section{References}

Cai, Y.Y., 2010. An Experimental Study of Non-coaxial Soil Behavior using Hollow Cylinder Testing. PhD Thesis, University of Nottingham, Nottingham, UK.

Cai, Y.Y., Yu, H.S., Wanatowski, D., et al., 2013. Noncoaxial behavior of sand under various stress paths. Journal of Geotechnical and Geoenvironmental Engineering, 139(8): 1381-1395. [doi:10.1061/(ASCE)GT.1943-5606.0000854]

Gutierrez, M., Ishihara, K., 2000. Non-coaxiality and energy dissipation in granular materials. Soils and Foundations, 40(2):49-59.

Gutierrez, M., Ishihara, K., Towhata, I., 1991. Flow theory for sand during rotation of principal stress direction. Soils and Foundations, 31(4):121-132.

Hight, D.W., Gens, A., Symes, M.J., 1983. The development of a new hollow cylinder apparatus for investigation the effects of principal stress rotation in soils. Geotechnique, 33(4):355-383

Hong, W., Lade, P., 1989. Strain increment and stress directions in torsion shear tests. Journal of Geotechnical Engineering, 115(10): 1388-1401.

Kumruzzaman, M., Yin, J.H., 2010. Influences of principal stress direction and intermediate principal stress on the stress-strain-strength behaviour of completely decomposed granite. Canadian Geotechnical Journal, 47(2): 164-179. [doi:10.1139/T09-079]

Lade, P.V., Kirkgard, M.M., 2000. Effects of stress rotation and changes of $b$-values on cross-anisotropic behavior of natural, $K_{0}$-consolidated soft clay. Soils and Foundations, 40(6):93-105.

Lade, P.V., Nam, J., Hong, W.P., 2009. Interpretation of strains in torsion shear tests. Computers and Geotechnics, 36(1-2):211-225. [doi:10.1016/j.compgeo.2008.02.001]

Li, X., Yu, H.S., 2013a. Micromechanics of deformation non-coaxiality in granular materials. Proceedings of Powders and Grains, p.1214-1217. [doi:10.1063/1.4812156]

Li, X., Yu, H.S., 2013b. On the stress-force-fabric relationship for granular materials. International Journal of Solids and Structures, 50(9):1285-1302. [doi:10.1016/j.ijsolstr.2012. 12.023]

Miura, K., Miura, S., Toki, S., 1986. Deformation behavior of anisotropic dense sand under principal stress axes rotation. Soils and Foundations, 26(1):36-52.

Nakata, Y., Hyodo, M., Murata, H., 1997. Non-coaxiality of sand subjected to principal stress rotation. In: Asaoka, A., Adachi, T., Oka, F. (Eds.), Deformation and Progressive Failure in Geomechanics, Pergamon Press, p.265-270.

Ohkawa, H., Kuwano, J., Nakada, T., et al., 2011. Yielding characteristic and non-coaxiality of Toyoura sand on $p$ '-constant shear stress plane. Soils and Foundations, 
51(1):179-190.

Pradel, D., Ishihara, K., Gutierrez, M., 1990. Yielding and flow of sand under principal stress axes rotation. Soils and Foundations, 30(1):87-99.

Roscoe, K.H., Bassett, R.H., Cole, E.R.L., 1967. Principal axes observed during simple shear of a sand. Proceedings of the 4th European Conference on Soil Mechanics and Geotechinical Engineering, Oslo, Norway, p.231-237.

Sãyao, A., Vaid, Y.P., 1996. Effect of intermediate principal stress on the deformation response of sand. Canadian Geotechnical Journal, 33(5):822-828. [doi:10.1139/t96108-328]

Shen, Y., 2007. Experimental Study on Effect of Variation of Principal Stress Orientation on Undisturbed Soft Clay. $\mathrm{PhD}$ Thesis, Zhejiang University, Hangzhou, China (in Chinese).

Symes, M.J., Gens, A., Hight, D.W., 1984. Undrained anisotropy and principal stress rotation in saturated sand. Géotechnique, 34(1):11-27.

Symes, M.J., Gens, A., Hight, D.W., 1988. Drained principal stress rotation in saturated sand. Géotechnique, 38(1): 59-81.

Tong, Z., Zhang, J., Yu, Y., et al., 2010. Drained deformation behavior of anisotropic sands during cyclic rotation of principal stress axes. Journal of Geotechnical and Geoenvironmental Engineering, 136(11):1509-1518. [doi:10. 1061/(ASCE)GT.1943-5606.0000378]

Wong, R.K.S., Arthur, J.R.F., 1986. Sand sheared by stresses with cyclic variations in direction. Géotechnique, 36(2): 215-226

Yan, J.J., Zhou, J., Guan, L.B., et al., 2013. Experimental study on non-coaxiality and influence factors of intact Hangzhou soft clay. Chinese Journal of Geotechnical Engineering, 35(1):96-102 (in Chinese).

Yang, Y., Yu, H.S., 2006. Application of a non-coaxial soil model in shallow foundations. Geomechanics and Geoengineering, 1(2):139-150. [doi:10.1080/17486020600 $777101]$

Yu, H.S., Yuan, X., 2006. On a class of non-coaxial plasticity models for granular soils. Proceedings of the Royal Society A: Mathematical, Physical \& Engineering Sciences, 462(2067):725-748. [doi:10.1098/rspa.2005.1590]

Zheng, H.B., 2011. Experimental Study of Reconstituted Clay and Intact Clay under Principal Stress Rotation. MS Thesis, Zhejiang University, Hangzhou, China (in Chinese).

\section{中文概要：}

本文题目: 主应力轴旋转条件下粘土的各向异性和非共轴特性

Undrained anisotropy and non-coaxial behavior of clayey soil under principal stress rotation

研究目的：研究主应力轴旋转条件下粘土的非共轴塑性流动规律和内在机理, 并分析土体初始各向异性、 中主应力系数、剪应力水平等对非共轴塑性流动特性的影响。

创新要点: 对主应力轴旋转条件下粘土塑性应变增量方向的规律和内在机理及影响因素进行分析, 为考虑 主应力轴旋转影响的粘土本构模型的建立提供了试验依据。

研究方法: 通过对比试验, 研究原状粘土和重塑粘土的非共轴塑性流动特性, 对非共轴塑性流动的规律和 内在机理及影响因素进行分析。

重要结论: 主应力旋转剪切条件下, 粘土的塑性主应变增量方向与主应力方向存在显著差异。非共轴特性 不完全取决于土体的各向异性特性, 受应力路径的影响也较大。 